\title{
The Fiscal Effect of U.S. Immigration: A Generational- Accounting Perspective
}

\author{
Alan J. Auerbach \\ Universify of California, Berkeley and NBER
}

\section{Philip Oreopoulos}

University of California, Berkeley

\section{EXECUTIVE SUMMARY}

Past research traditionally has adopted a static, cross-sectional approach in assessing the net effect of immigrants on the economy's fiscal position. But this approach is inadequate, for it fails to account for the future impact of current immigrants and their offspring. To overcome this shortcoming and avoid misleading conclusions, a dynamic analysis is necessary. The recently developed tool of generational accounting provides an ideal framework for such analysis, for it also permits a comparison of the fiscal effects of immigration policy with those of other policies.

This paper amends and then applies the technique of generational accounting to measure the fiscal effects of immigration. Among its findings are:

We gratefully thank Barry Edmonston, Jagadeesh Gokhale, Ron Lee, Tim Miller, and John Sturrock for their provision of data and projections necessary for this paper's computations. We thank Tom Barthold, Jagadeesh Gokhale, Ron Lee, Jim Poterba, Kjetil Storesletten, Jan Walliser, and Ronald Wendner for comments on earlier drafts, and the Burch Center for Tax Policy and Public Finance, the Social Sciences and Humanities Research Council of Canada, and the Center for the Economics and Demography of Aging (through NIA grant P20 AG12839) for financial support. 
1) The recent improvement in the U.S. fiscal picture reduces the potential fiscal benefits of immigration. With future generations projected to bear a lower net fiscal burden than under previous forecasts, there is less to be gained by sharing this burden with new immigrants.

2) Changes in the level of immigration have an uncertain effect on fiscal balance, with the sign dependent on parameter choices and assumptions. However, the effect, whether positive or negative, is small in magnitude relative to the overall U.S. fiscal imbalance.

3) Of greater potential fiscal importance are changes in the composition of the immigrant population, in particular with respect to educational attainment.

Thus, to the extent that the debate over immigration policy has focused on the level rather than the composition of the immigrant population, this attention may have been misplaced.

\section{INTRODUCTION}

As a "nation of immigrants," the United States has experienced ebbs and flows both in the rate of immigration and in the attitudes of its citizens toward new immigrants. In recent years, the renewed strength of immigration to the United States has sparked a debate about the economic effects of immigration, focusing primarily on effects in the labor market (e.g., Card, 1996) and fiscal effects.

The debate over the fiscal burdens imposed by immigration culminated in such events as the November 1996 vote by California's electorate in favor of Proposition 187, a measure which, had it not been tied up in litigation, would have denied illegal immigrants and their children access to public assistance, social services, health care, and, notably, public education. But while some have seen immigrants as a fiscal drain, others have seen them as a potential solution to the fiscal pressures of an aging population: as a new source of taxpayers to keep the unfunded, age-based U.S. social insurance system of social security and Medicare from collapsing. In the face of such conflicting perspectives, only a quantitative analysis can determine the net fiscal effect of immigration. Such an analysis is one of this paper's goals.

Research in this area [surveyed in National Research Council (NRC), 1997. Chapter 61 traditionally has adopted a static, cross-sectional approach in assessing the new effect of immigrants on the economy's fiscal position. But such calculations are inadequate, for they do not take into account the future consequences of short-term changes in the level of immigration. For example, consider the cases of public education and social security. From cross-section analysis, a large population of school-age immigrants might appear to add fiscal pressure via added expenditures. 
But this calculation ignores the subsequent income taxes paid by these same immigrants in their adulthood, as well as by their native offspring, payments that might more than compensate for the increased spending. On the other hand, while a large working-age immigrant population might appear to lessen the fiscal burden of a pay-as-you-go social security system, these immigrants will eventually receive benefits from the same system, benefits that could exceed the taxes they paid in present value.

To overcome these shortcomings and avoid misleading conclusions, a dynamic analysis that takes the future consequences of immigration into account is necessary. A recent such analysis for the United States (NRC, 1997, Chapter 7, based largely on Lee and Miller, 1997) reached the conclusion that U.S. immigrants provide a net fiscal benefit in present value when account is taken of their own effect on tax receipts, transfers, and government purchases, as well as that of their descendents. While we use many of the data and projections from that research, we go beyond them in several respects.

First, we consider the effects of the recent changes in the U.S. fiscal outlook. Based on the more pessimistic fiscal projections of the time, the NRC study's results incorporated the assumption that the future would bring the tax increases and/or benefit cuts needed to stabilize the national debt. Without such measures of fiscal stringency, the fiscal benefits of a larger group of future taxpayers may be reduced or eliminated.

Second, we consider the impact of a changing immigration mix, in particular a change in the educational status of the immigrant population. Many of the critics of current U.S. immigration policy (e.g., Borjas, 1994) have argued that it is not the recent rise in immigration per se, but rather the decline in the earnings ability of immigrants, that is the source of pressure.

Finally, applying more fully an approach we used in our earlier paper (Auerbach and Oreopoulos, 1999), we perform our dynamic analysis using the techniques of generational accounting introduced by Auerbach, Gokhale, and Kotlikoff (1991) and applied subsequently by a number of others. Generational accounting allows us to go beyond calculations of the net impact of immigrants, to consider the impact of changes in immigration policy on the relative burdens of different age cohorts, and to compare the fiscal effects of immigration policy with those of other policies. This last comparison is useful in helping us judge the quantitative significance of changes in immigration policy.

Another of the paper's contributions is its adaptation of the generational accounting methodology to accommodate the presence of immigrants and immigration. In the past, generational accounts have typically ignored immigration, treating population changes resulting from immigration as if they resulted from a decline in mortality among natives in the 
immigrant's generation. That is, all members of a given generation at each. age were treated as survivors among the original U.S. residents of that generation. Thus, each generation's account included the projected taxes and transfers of subsequent immigrants of the same cohort and therefore did not reflect the net fiscal burdens of current residents of that generation. For example, if immigrants were primarily aged and received certain old-age benefits, these benefits would have been treated as additional transfer payments to current residents, leading to an understatement of the typical resident's lifetime fiscal burden. For countries with significant immigrant populations, such a procedure could provide a distorted picture of the fiscal burdens of current generations and hence of the gap between current and future generations implied by a given fiscal policy.

Because of the importance of this change in methodology, we begin. our analysis with a description of the new approach to generational accounting and a comparison of this approach and the previous one. After discussing our data sources, we turn to an analysis of the effects of U.S. immigration on fiscal balance and generational burdens. Among our results are:

1. The recent improvement in the U.S. fiscal picture reduces the potential fiscal benefits of immigration. With future generations projected to bear a lower net fiscal burden than under previous forecasts, there is less to be gained by sharing this burden with new immigrants.

2. Changes in the level of immigration have an uncertain effect on fiscal balance, with the sign dependent on parameter choices and assumptions. However, the effect, whether positive or negative, is small in magnitude relative to the overall U.S. fiscal imbalance.

3. Of greater potential fiscal importance are changes in the composition of the immigrant population, in particular with respect to educational attainment.

Thus, to the extent that the debate over immigration policy has focused on the level rather than the composition of the immigrant population, this attention may have been misplaced.

\section{GENERATIONAL ACCOUNTING: EXISTING METHODOLOGY}

We begin with a brief review of the standard generational accounting methodology. For further discussion, the reader is referred to Auerbach, Gokhale, and Kotlikoff (1991) or Auerbach and Kotlikoff (1999). 
Generational accounting is based on the government's intertemporal budget constraint. This constraint, written as equation (1), requires that the present value of all future net tax payments made by current and future generations be sufficient to cover the present value of future government consumption as well as service the government's initial net indebtedness:

$$
\sum_{s=0}^{D} N_{t, t-s}+\sum_{s=1}^{s} N_{t, 1+s}(1+r)^{-s}=\sum_{s=t}^{\infty} G_{s}(1+r)^{-(s-t)}-W_{i} .
$$

The first summation on the left side of (1) adds together the generational accounts (the present value of the remaining lifetime net payments) of existing generations. The term $N_{t, t-s}$ stands for the account of the generation born in year $t-s$. The index $s$ in this summation runs from age 0 to age $D$, the maximum length of life. ${ }^{2}$

The second summation on the left side of (1) adds together the present values of remaining net payments of future generations, with s representing the number of years after year $t$ that the generation is born. The summation on the right side of (1) expresses the present value of government consumption. In this summation the value of government consumption in each year $s, G_{s}$ is discounted by the pretax real interest rate $r$. The remaining term on the right side, $W_{i}^{*}$, is the government's net wealth in year $t$-its assets minus its explicit debt. As in past applications, we ignore real government assets and the offsetting flows from such assets in calculating $W_{i}^{*}$ and $G_{s}$, respectively, so that $-W_{i}^{g}$ reduces to the value of government debt.

Equation (1) indicates the zero-sum nature of intergenerational fiscal policy. Holding the present value of government consumption fixed, a reduction in the present value of net taxes extracted from current generations [a decline in the first summation on the left side of (1)] necessitates an increase in the present value of net tax payments of future generations.

The account $N_{l, k}$ is defined by

$$
N_{t, k}=\sum_{s=s}^{k+D} T_{s, k} P_{s, k}(1+r)^{-(s-\kappa)},
$$

\footnotetext{
1 The constraint does not assume that government debt is ever fully paid off, merely that the debt grows less quickly than the rate of discount, i.e., it does not explode. Thus, it is consistent with the long-run existence of government deficits, as long as these deficits are smaller than the amount needed simply to service the level of outstanding debt.

${ }^{2}$ Hence, the first term of this summation is $N_{s, y}$ which is the present value of net payments of the generation born in year $t_{i}$ the last term is $N_{t, t \rightarrow D}$, the present value of remairing net payments of the oldest generation alive in year $t$, namely those born in year $t-D$.
} 
where $\kappa=\max (t, k)$. For generations born prior to year $t_{f}$ the summation begins in year $t$. For generations born in year $k>t$, the summation begins in year $k$.

In expression (2), $T_{s, k}$ stands for the projected average net tax payment made to the government in year s by a member of the generation born in year $k$, and $P_{s, k}$ stands for the number of residents in year $s$ belonging to the cohort born in year $k$. As discussed above, the traditional generational accounting methodology treats each of these as survivors of those present in year $k$; immigrants have their taxes and transfers attributed to natives of the same cohort.

A set of generational accounts is simply a set of values of $N_{t, k}$ one for each existing and future generation, with the property that the combined present value adds up to the right side of equation (1). Though we distinguish male and female cohorts in the results presented below, we suppress sex subscripts in equation (1) and (2) to ease notation.

Note that generational accounts reflect only taxes paid less transfers received. With the occasional exception of government expenditures on education, the accounts presented in past research typically have not imputed to particular generations the value of the government's purchases of goods and services. Therefore, the accounts do not show the full net benefit or burden that any generation receives from government policy as a whole, although they can show a generation's net benefit or burden from a particular policy change that affects only taxes and transfers. Thus generational accounting tells us which generations will pay for government spending rather than telling us which generations will benefit from that spending. Another characteristic of generational accounting is that, like deficit accounting, it does not incorporate induced behavioral effects or macroeconomic responses of policy changes. ${ }^{3}$ As a corollary, it does not incorporate the deadweight loss of taxation in its measure of fiscal burden, again following the tradition of budget incidence analysis.

The left side of equation (1) is estimated assuming current projected fiscal policy and then compared with the right side. If the sum of the current and future generational accounts is smaller in present value than total future government consumption and initial net debt, current policy is unsustainable and a policy that adjusts at least part of the equation is

${ }^{3}$ For further discussion, see Fehr and Kotlikoff (1999), who use the Auerbach-Kotlikoff simulation model to assess the effect of general-equilibrium effects on generational accounts. They find that the accounts typically provide a good approximation of the full general-equilibrium effect. Integrating our disaggregated accounts into a general-equilibrium model is an interesting topic for future research. Progress in this direction has been made by Storesletten (2000), who incorporates three skill classes of immigrants in an. Auerbach-Kotlikoff-type simulation model to study the impact of changes in the immigration mix on U.S. fiscal balance. 
required. Of course, there is no unique way to make this adjustment. Our base case assumes that any residual amount needed to satisfy the government's budget constraint will be borne entirely by future generations. The traditional approach has beer to spread this burden among future generations in such a way that the average present-value lifetime net tax payment per initial member of each future generation is constant except for productivity growth. Again, the old methodology did not allow for the fact that some of these taxes would actually be paid by immigrants, and did not separate the burdens of immigrants from those of natives.

\section{GENERATIONAL ACCOUNTING AND IMMIGRATION}

To take explicit account of the effect of immigrants, we rewrite equation (1), breaking its components into those attributable to immigrants and those attributable to natives:

$\sum_{s=0}^{D}\left(N_{t, t-s}+F_{t, t-s}\right)+\sum_{s=1}^{\infty}\left(N_{t, t+s}+F_{t, t+s}\right)(1+r)^{-s}=\sum_{s=1}^{\infty} G_{s}(1+r)^{-\{s-t)}-W_{t}^{g}$,

where we now define $N_{t, t-s}$ to be the account of the natize generation born in year $t-s$, and define $F_{t, t-s}$ to be the account for all others born in year $t-s$. Equation (2) still provides the definition of $N_{t, k}$, now the factors $T_{s, k}$ represent the net tax payments for natives, and the population levels $P_{s, k}$ stand for the number of natives born in year $k$ that survive at least until year s. Thus, the two sets of terms $F_{k, k}$ in equation (3) represent, respectively, the accounts for all immigrants to existing cohorts and the accounts for all immigrants to future cohorts. That is,

$$
F_{t, k}=\sum_{s=k}^{k+D} T_{s, k}^{*} P_{s, k}^{*}(1+r)^{-(s-*)},
$$

where, as in (2), $\kappa=\max (t, k)$, and where $T_{s, k}^{*}$ is the projected per capita net tax payment and $P_{s, k}^{*}$ is the number of residents in year $s$ for the immigrant generation born in year $k$. The evolution of $P_{s_{1}, k}^{*}$ over time (i.e., holding $k$ fixed and varying s) will reflect not only mortality, but also additional immigration and emigration of previous immigrants. Values of $T_{s, k}^{*}$ will typically differ from those of natives. Indeed, this difference is a crucial element of the debate over the fiscal effects of immigrants. We return to this issue below, after discussing data sources and methodology.

Because the accounts defined by equation (4) incorporate the net taxes 
resulting from additional immigration after year $\kappa$, there is no simple way to divide them by the associated year- $k$ population $P_{s, k}^{*}$ to produce generational accounts that are comparable to the per capita accounts of natives. ${ }^{4}$ Thus, one should view the construction of the accounts in (4) primarily as a necessary step in deriving correct accounts for natives.

Given adequate data, calculation of the burdens on existing generations remains straightforward after this decomposition: we simply allocate burdens to natives and immigrants based on the taxes and transfers attributable to each group. However, for future generations, which the standard methodology treats as a residual group, there is no obvious analogy to the procedure used in the no-immigrant case. We can no longer simply assign to each future native generation the same (adjusted for growth) per capita generational account, for this leaves open the question of what adjustment should be imposed on future immigrants.

One approach might be to extend the current assumption used to distinguish future burdens by sex, requiring that the percentage per capita increase in generational accounts be the same for natives and immigrants. ${ }^{5}$ But this is unappealing given that immigrants have a very different population structure than natives. It seems implausible that any realistic policy to raise the fiscal burdens on future generations would have the same percentage effect on the lifetime fiscal burdens of natives and immigrants. Immigrants inherently have a different lifetime pattern of U.S. residence and hence of U.S. taxes and transfers. Indeed, as immigrants arrive at different ages, it is not even clear how they should be aggregated to perform such a calculation.

To deal with this problem, we propose an alternative method of assigning the residual. The method involves first calculating the burdens on future generations (both native and immigrant) under current policy, specifying some combination of tax and transfer instruments to be adjusted, and then adjusting these instruments proportionally for future generations until equation (3) is satisfied. This allocation of the extra burden on future generations typically will yield different percentage increases for men and women, and for natives and immigrants, but will

\footnotetext{
* For example, because essentially all first-generation immigrants arrive after age 0 , theit: aggregate age-0 account is attributable to net taxes paid by individuals not in the population as of age 0 ; the per capita generational account would appear to be infinite.

5 A recent analysis using generational accounting to study immigration in Germany (Bonin, Raffelhüschen, and Walliser, 1998) did rely on such an assumption. That paper also assumed that the age structure of immigrants among future generations was the same as that of current immigrants, an assumption that we do not make here.
} 
be based on a concrete change in actual policy variables. Because the allocation also depends on the tax or transfer components being adjusted, we consider different policy combinations, namely, proportional increases in all taxes, proportional decreases in all transfers, or the combination of the two (with the same proportional changes in taxes and transfers). We also consider making the proportional adjustment of taxes and transfers immediately, so that the new policy affects current as well as future generations.

\section{DATA SOURCES}

Construction of generational accounts requires population data and projections, tax and transfer profiles for different demographic groups within each cohort, projections for the path of government purchases, a value for the initial stock of government debt, and assumption about the government's discount rate.

For much of this, we rely on the assumptions and data used in the recently-published calculation for the United States by Gokhale, Page, and Sturrock (1999, hereafter GPS). However, we substitute more recent aggregate projections provided by one of the authors, John Sturrock, based on the spring 1999 CBO long-run forecast. These aggregate projections generate a considerably smaller fiscal imbalance than was reported by GPS, whose projections we used in an earlier paper (Auerbach and Oreopoulos, 1999). The new data set includes aggregate projections for the growth of government spending $G_{i}$ and aggregate taxes and transfers through the year 2070 . We assume that aggregate taxes and transfers grow with labor productivity after 2070 at a real per capita rate of 1.2 percent. For government purchases after 2070, we benchmark age-based profiles of government spending used by Auerbach, Gokhale, and Kotlikoff (1991) to the 2070 aggregate, and assume that these profiles grow with the rate of labor productivity thereafter. Thus, governmentspending growth is permitted to deviate from the general growth tate to the extent that there are shifts in the age structure of the population. Finally, we follow GPS in assuming a 1.2-percent rate of labor productivity growth after 2070 , and a real discount rate of 6 percent. As we adopt a base year of 1998 instead of 1995, we use an updated value of $W_{t}^{g}=-2.0$ trillion.

As to tax and transfer profiles, GPS disaggregate only by sex, and not by nativity, and so we must supplement them with data from another source. Tax and transfer policies broken down by nativity, but not by sex, come from estimates by Lee and Miller (1997). We apply an algo- 
rithm, described in the appendix, to combine the two sets of profiles to generate tax and transfer profiles by both sex and nativity. ${ }^{6}$ As the appendix also discusses, we then use further information about how these profiles vary by educational status to adjust the profiles of future immigrants to take account of changes over time in the composition of the immigrant population.

For population projections, we simply use an alternative source that provides information at a more disaggregate level. These alternative population projections were provided by Barry Edmonston based on an adaptation of the population projection model in NRC (1997, Appendix 3.A). The model generates annual population projections through the year 2100 , broken down by age, sex, and nativity, the last of which has three categories: first-generation immigrants, second-generation immigrants (i.e., native children of immigrants), and all others, to whom we refer simply as natives. We assume a stationary population after $2100 .^{7}$ Like the profiles by immigrant status, which in principle cover all foreign-born individuals and not just legal immigrants, the estimated immigrant population includes not only legal immigrants, but illegal immigrants as well. ${ }^{8}$

\section{INITIAL RESULTS: EFFECTS OF THE CHANGE IN METHODOLOGY}

Table 1 presents generational accounts constructed under different assumptions, to illustrate the effects of the changes in methodology just described. For each simulation, the table presents the generational accounts for existing generations of males and females at five-year intervals and the accounts for future generations implied by the need to satisfy intertemporal fiscal balance. Our base year is 1998; those born in 1998 represent age 0 in the table, and future generations begin with those born in 1999.

The first two columns present the accounts for males and females

\footnotetext{
* The algorithm requires additional assumptions regarding relative patterns across nativity groups. We choose the restriction that the male-female ratio (per capita) for each tax and transfer component is constant at each age across the three nativity groups. For example, we assume that the ratio of income taxes per age-46 male to income taxes per age-46 female is the same for first-generation immigrants, second-generation immigrants, and natives.

7 Whether we specify the population to be constant after 2100 or 2200 does not significantly alter our results, because the generational accounting methodology assigns relatively little weight to the distant future.

${ }^{8}$ For further discussion, see NRC (1997, pp. 88, 306). The hypothetical no-immigrant experiment considered below eliminates all immigrant, legal and illegal.
} 
based on the traditional methodology, using the aggregate male and female tax and transfer profiles from GPS, the updated aggregate projections, and our alternative population projections. The accounts for existing generations show the standard pattern, higher in general for men than women and rising and then falling with age as taxes and then transfers because a more significant factor. They also show an imbalance between current and future generations of just 8.5 percent, down substantially from the 72-percent imbalance found by GPS. Part of the explanation lies in our faster projected population growth. With initial debt and projected growth in government purchases through 2070 given, higher population translates into lower per capita burdens. As discussed in our earlier paper, this change from the assumptions of GPS, alone, would reduce the fiscal imbalance from 72 percent to 54 percent. However, the remaining drop is due entirely to the sharp improvement in the fiscal picture embodied in the newer aggregate projections.

The next set of calculations shows the effect of the alternative method of allocating the residual burden to future generations, by cutting all transfers and increasing all taxes in a proportional manner. The accounts in these columns still aggregate the taxes and transfers of immigrants with those of natives. Because the only change here is in the allocation of burden among future generations, the accounts for existing generations are unchanged. Listed below the accounts for current generations are the percentage increase in taxes and cut in transfers, as well as the corresponding percentage increases, relative to current newborns, in the accounts of future generations of males and females.

Note that the percentage increases in the generational accounts are no longer equal for males and females, because the new methodology adjusts taxes and transfers, rather than overall burdens, proportionally. As can be seen by inspection of equation (2) and the definition of the net tax payment $T_{s, k}$ increasing the accounts proportionally, regardless of the pattern of taxes and transfers, would require an equal percentage increase in all taxes and an equal percentage increase in all transfers. ${ }^{9}$ Moreover, this approach doesn't necessarily impose an equal per capita net tax burden (adjusted for growth) on all future generations. Even though tax and transfer profiles are the same, changes in mortality (and, in this simulation, immigration patterns as well) will cause different generations to have different lifetime tax burdens. Thus, the "future generation" listed

${ }^{9}$ Indeed, the traditional approach, in implicitly raising taxes and raising transfers proportionally, can lead to strange results. For example, if current newborn males have positive generational accounts and females have negative generational accounts, and burdens must be raised on future generations, the standard methodology calls for making the burdens on females more negative. 
TABLE 1

Generational Accounts: Altemative Methodologies ${ }^{(a)}$

\begin{tabular}{|c|c|c|c|c|c|c|c|c|}
\hline \multirow[b]{2}{*}{ Age } & \multicolumn{2}{|c|}{ Traditional method } & \multicolumn{2}{|c|}{$\begin{array}{l}\text { New method } \\
\text { of allocating } \\
\text { burden on } \\
\text { future } \\
\text { generations }\end{array}$} & \multicolumn{2}{|c|}{$\begin{array}{l}\text { New method of } \\
\text { allocating burden } \\
\text { on natives only }\end{array}$} & \multicolumn{2}{|c|}{$\begin{array}{l}\text { New method, } \\
\text { natives only, future } \\
\text { 2nd-generation } \\
\text { profiles adjusted }\end{array}$} \\
\hline & Males & Females & Males & Females & Males & Females & Males & Females \\
\hline 0 & 116.2 & 76.0 & 116.2 & 76.0 & 106.9 & 71.0 & 106.9 & 71.0 \\
\hline 5 & 144.6 & 92.9 & 144.6 & 92.9 & 133.9 & 86.7 & 133.9 & 86.7 \\
\hline 10 & 176.1 & 111.7 & 176.1 & 111.7 & 165.3 & 105.4 & 165.3 & 105.4 \\
\hline 15 & 215.7 & 135.0 & 215.7 & 135.0 & 204.9 & 128.7 & 204.9 & 128.7 \\
\hline 20 & 257.3 & 159.3 & 257.3 & 159.3 & 249.9 & 155.0 & 249.9 & 155.0 \\
\hline 25 & 279.4 & 169.3 & 279.4 & 169.3 & 277.6 & 169.1 & 277.6 & 169.1 \\
\hline 30 & 273.5 & 161.2 & 273.5 & 161.2 & 277.0 & 164.8 & 277.0 & 164.8 \\
\hline 35 & 257.7 & 148.0 & 257.7 & 148.0 & 264.1 & 154.3 & 264.1 & 154.3 \\
\hline 40 & 228.3 & 124.1 & 228.3 & 124.1 & 236.8 & 132.6 & 236.8 & 132.6 \\
\hline 45 & 179.0 & 84.3 & 179.0 & 84.3 & 185.7 & 91.4 & 185.7 & 91.4 \\
\hline 50 & 113.3 & 33.5 & 113.3 & 33.5 & 117.6 & 39.0 & 117.6 & 39.0 \\
\hline 55 & 35.4 & -24.8 & 35.4 & -24.8 & 36.2 & -22.1 & 36.2 & -22.1 \\
\hline
\end{tabular}




\begin{tabular}{|c|c|c|c|c|c|c|c|c|}
\hline $\begin{array}{l}60 \\
65 \\
70 \\
75\end{array}$ & $\begin{array}{r}-48.3 \\
-109.5 \\
-117.5 \\
-110.2\end{array}$ & $\begin{array}{r}-84.8 \\
-125.8 \\
-128.6 \\
-120.7\end{array}$ & $\begin{array}{r}-48.3 \\
-109.5 \\
-117.5 \\
-110.2\end{array}$ & $\begin{array}{r}-84.8 \\
-125.8 \\
-128.6 \\
-120.7\end{array}$ & $\begin{array}{r}-49.0 \\
-111.9 \\
-118.3 \\
-107.6\end{array}$ & $\begin{array}{r}-83.6 \\
-126.8 \\
-128.7 \\
-119.0\end{array}$ & $\begin{array}{r}-49.0 \\
-111.9 \\
-118.3 \\
-107.6\end{array}$ & $\begin{array}{r}-83.6 \\
-126.8 \\
-128.7 \\
-119.0\end{array}$ \\
\hline $\begin{array}{l}80 \\
85 \\
90\end{array}$ & $\begin{array}{l}-92.4 \\
-78.4 \\
-59.5\end{array}$ & $\begin{array}{r}-102.4 \\
-81.8 \\
-60.5\end{array}$ & $\begin{array}{l}-92.4 \\
-78.4 \\
-59.5\end{array}$ & $\begin{array}{r}-102.4 \\
-81.8 \\
-60.5\end{array}$ & $\begin{array}{l}-91.4 \\
-78.2 \\
-59.0\end{array}$ & $\begin{array}{r}-101.6 \\
-81.7 \\
-60.3\end{array}$ & $\begin{array}{l}-91.4 \\
-78.2 \\
-59.0\end{array}$ & $\begin{array}{r}-101.6 \\
-81.7 \\
-60.3\end{array}$ \\
\hline \multicolumn{9}{|l|}{ fufure Generations } \\
\hline $\begin{array}{c}\% \text { differences } \\
\text { Taxes \& Transfers }\end{array}$ & \multicolumn{2}{|c|}{8.5} & $\begin{array}{r}10.2 \\
128.1 \\
\end{array}$ & $\begin{array}{l}12.0 \\
85.1\end{array}$ & $\begin{array}{r}11.3 \\
118.8\end{array}$ & $\begin{array}{l}12.5 \\
79.9 \\
\end{array}$ & $\begin{array}{r}12.3 \\
120.1 \\
\end{array}$ & $\begin{array}{l}13.9 \\
80.9 \\
\end{array}$ \\
\hline$\%$ change & & & \multicolumn{2}{|c|}{6.6} & \multicolumn{2}{|c|}{6.5} & \multicolumn{2}{|c|}{7.3} \\
\hline Taxes only & & & & & & & 121.9 & 80.7 \\
\hline$\%$ change & & & & & & & \multicolumn{2}{|c|}{10.1} \\
\hline Transfers only & & & & & & & 118.1 & 81.2 \\
\hline$\%$ change & & & & & & & \multicolumn{2}{|c|}{25.8} \\
\hline
\end{tabular}

(a) In thousands of dollars; $r=.06, g=.012$. Base year 1998 . 
in the table refers to the first future generation only, the cohort born in 1999. Given the change in methodology, there is no assurance that the burden on future generations will be the same as in the first simulation, and indeed, the burdens on future males and females born in 1999 are projected to be higher here for both males and females. The explanation for this increase lies primarily in the fact that members of later generations are projected to live longer. As longer life translates into an increase in transfer payments and hence a decline in net tax liabilities, a greater share of the fiscal burden must be placed on the initial future generations, while the burden on later generations will be smaller.

The third set of calculations presented in the table illustrates the further effects of distinguishing immigrants from others in the population. ${ }^{10} \mathrm{It}$ presents the generational accounts for natives based on equation (3), for the case in which the generational accounts of first- and second-generation immigrants are calculated separately. Before discussing these results, it is useful to look at the tax and transfer profiles underlying them. Profiles for immigrants and natives, derived from two different data sources using the algorithm described in the appendix, are displayed in Figures 1 through 3 . The figures present, for males and females separately, the age profiles for all per capita taxes, transfers, and taxes net of transfers, respectively.

As the figures show, differences between immigrants and natives are more significant on the tax side than on the transfer side. Indeed, we note from Figure $2 \mathrm{a}$ and $\mathrm{b}$ that while first-generation immigrants do receive more transfer payments per capita than natives in middle age, they actually receive less in old age. This is primarily due to lower social security benefits resulting from lower covered lifetime wages. On the other hand, taxes are substantially lower for first-generation immigrants than for natives (Figure 1a and b), and this carries over into the net tax profiles (Figure $3 a$ and $b$ ). Perhaps surprising is the position of the net tax profiles of second-generation immigrants above those of natives. While one would expect assimilation to bring these secondgeneration profiles above those of first-generation immigrants, their observed position suggests that today's second-generation immigrants and today's first-generation immigrants differ by more than just time since immigration. Thus, it may be inappropriate to use these profiles in projections for the future second-generation children of today's firstgeneration immigrants. We return to this issue shortly, when we discuss

10 The program used to produce these simulations, written to run using MATLAB version 5, is available at the Web site of the Burch Center for Tax Policy and Public Finance (hto:// emlab.berkeley.edu/users/burch/). 


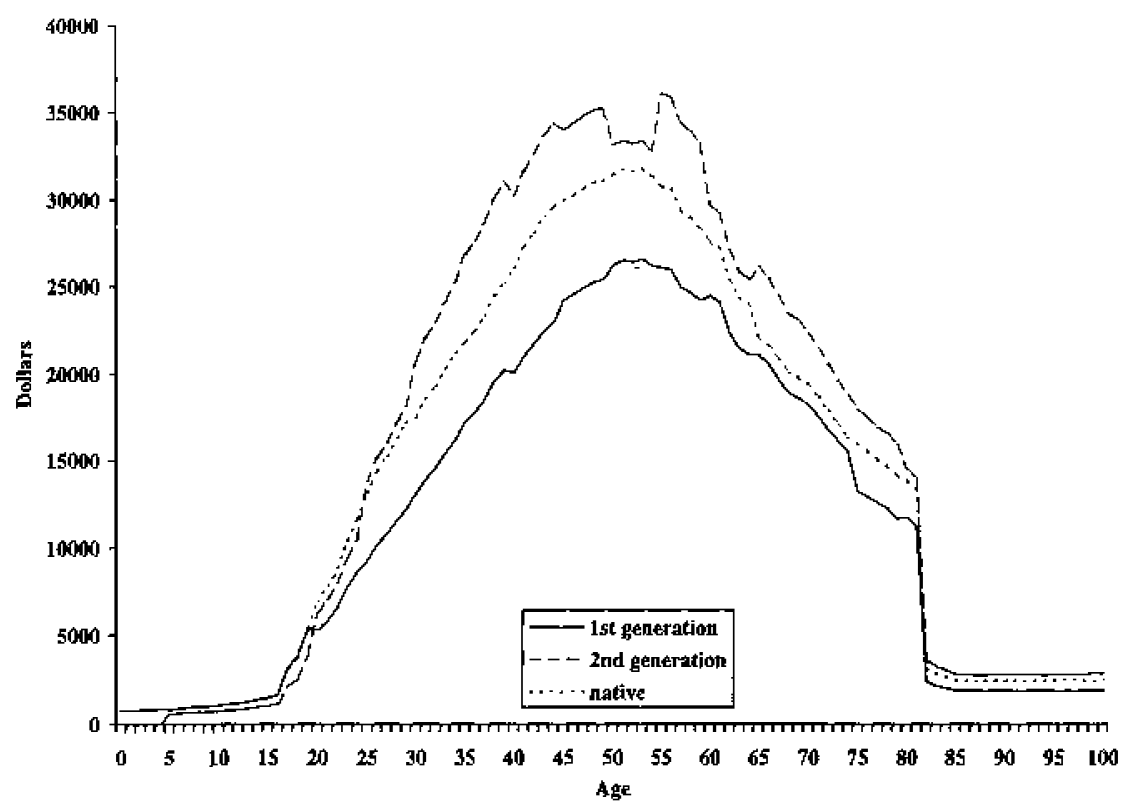

(a)

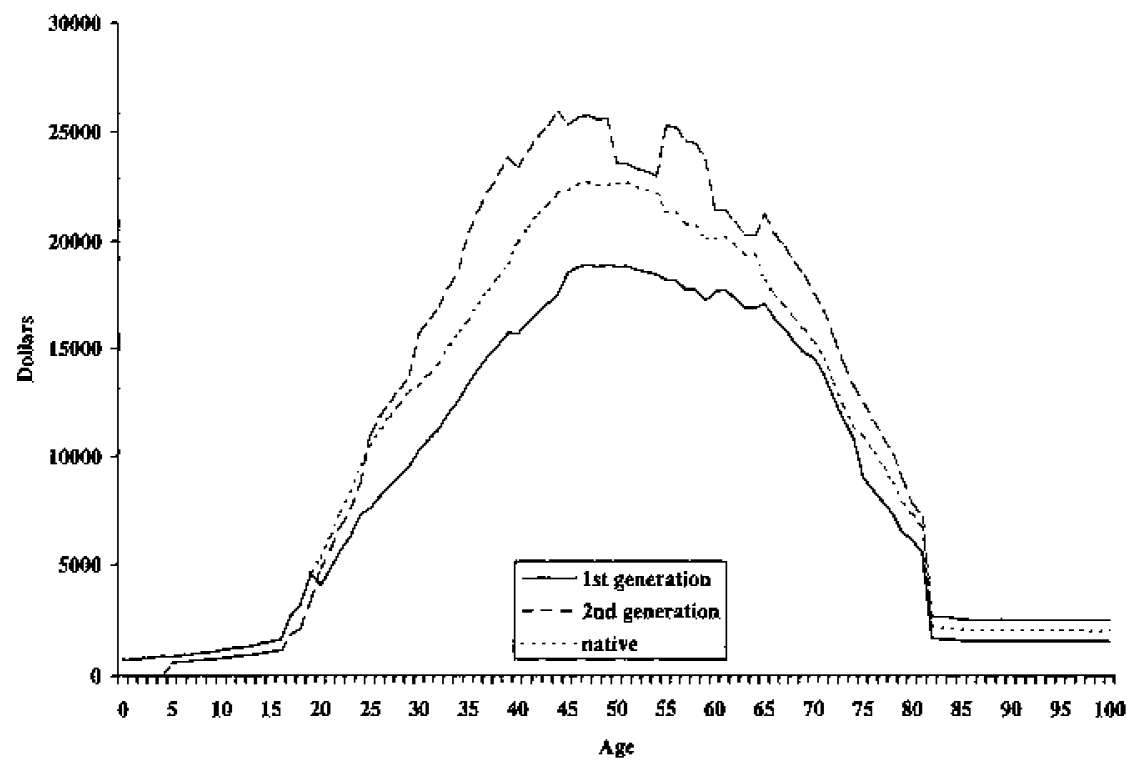

(b)

FIGURE 1. Annual Flows of per Capita Taxes, 1998: (a) Males, (b) Females 


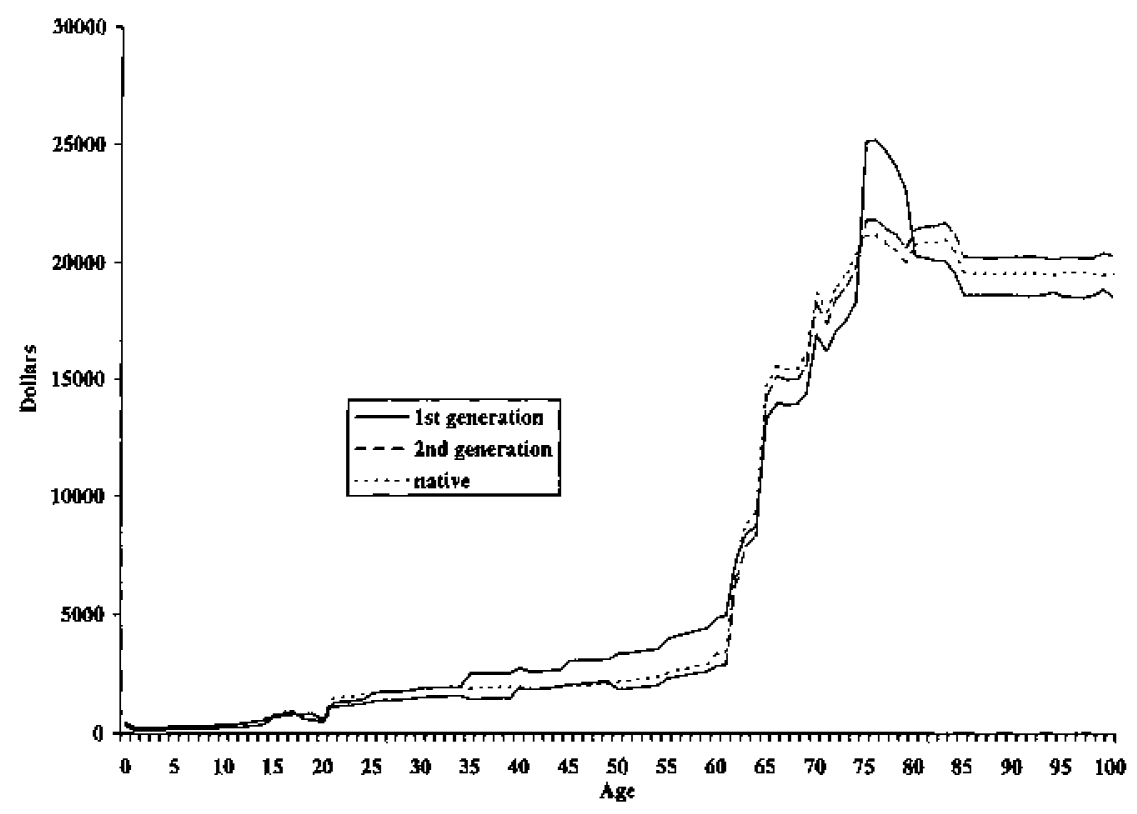

(a)

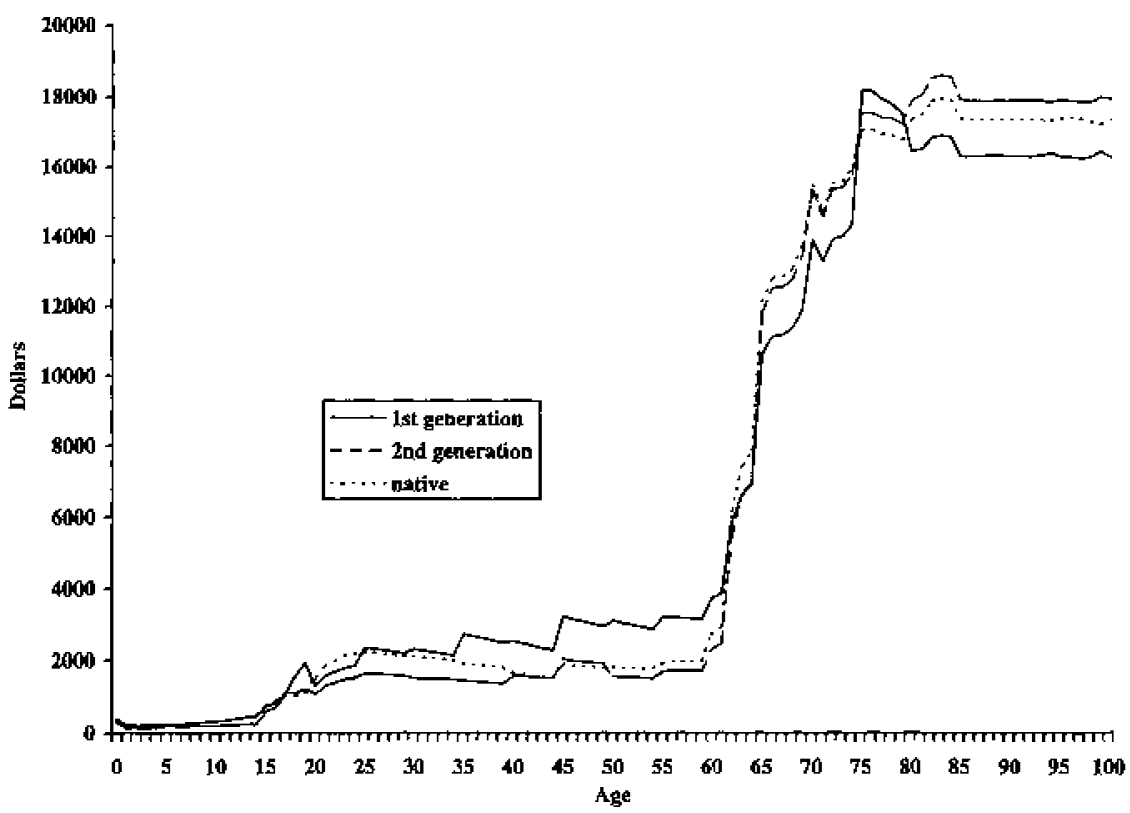

(b)

FIGURE 2. Annual Flows of per Capita Transfers, 1998: (a) Males, (b) Females 


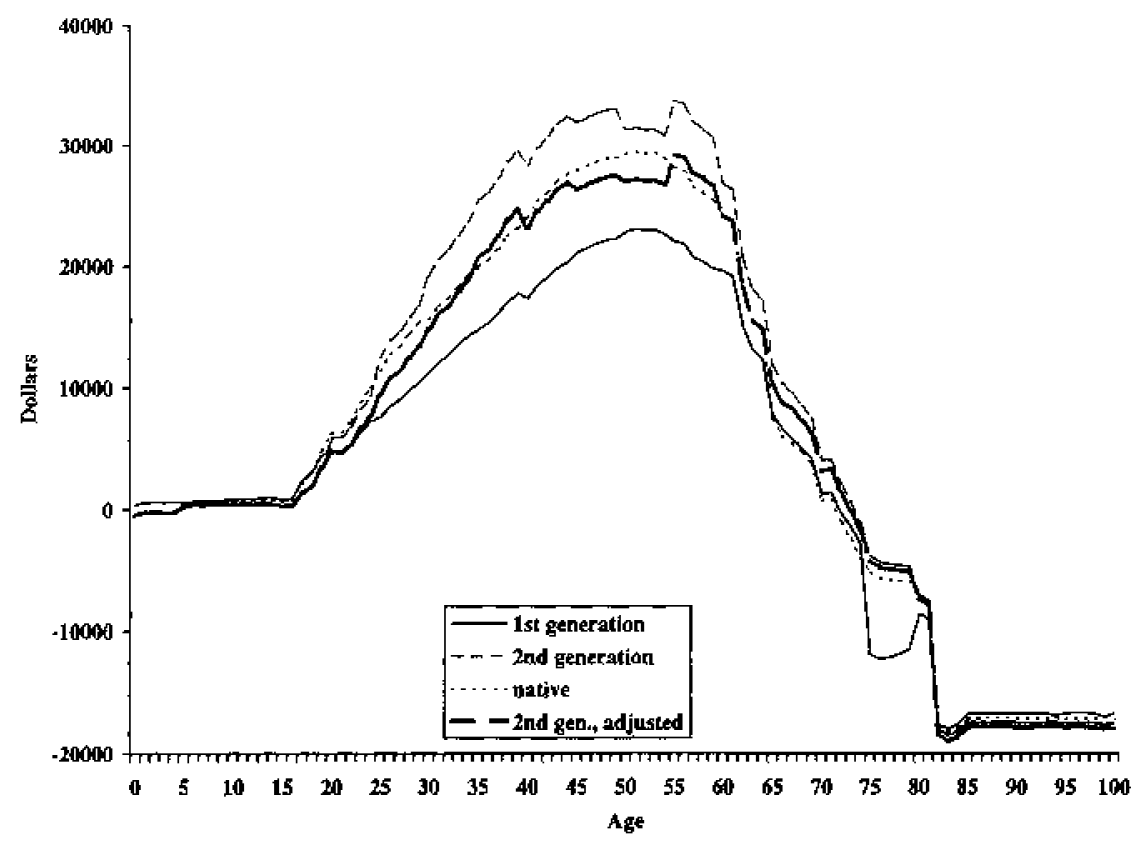

(a)

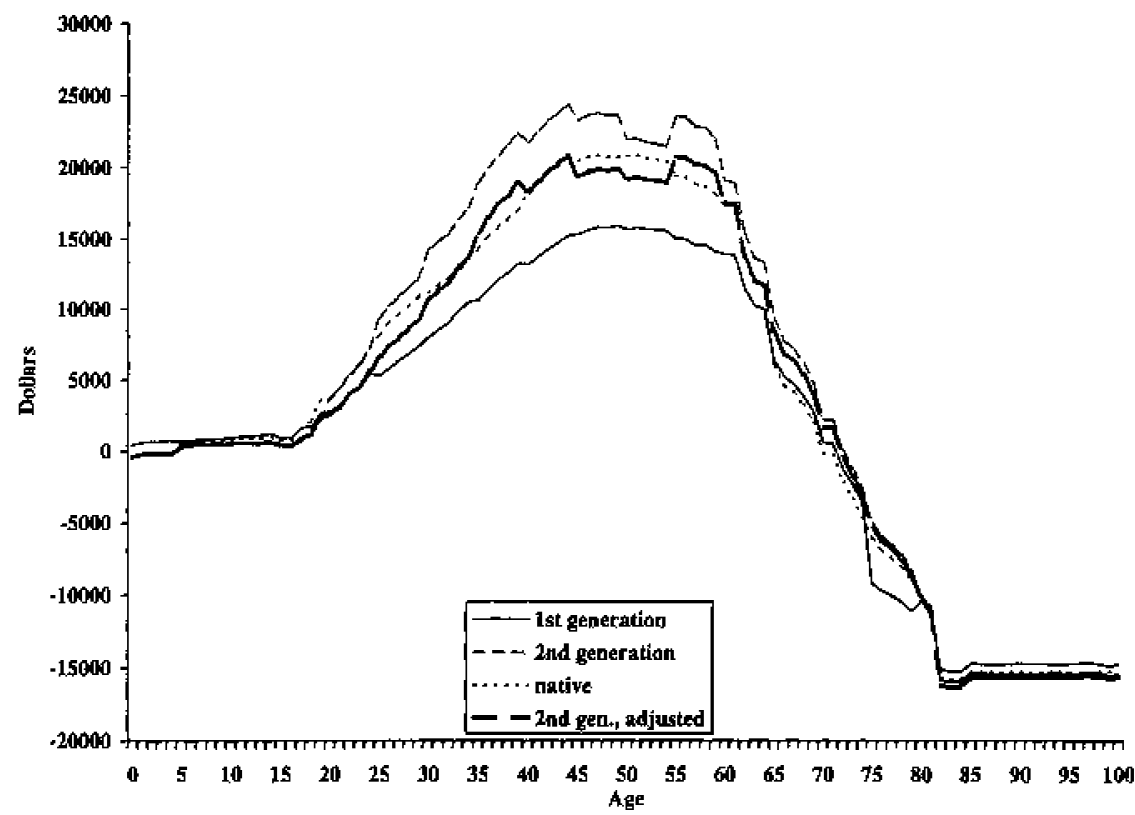

(b)

FIGURE 3. Annual Flows of per Capita Net Taxes: (a) Males, (b) Females 
the derivation of the adjusted second-generation profiles also shown in Figure $3 a$ and $b$.

Looking again at the third set of results in Table 1 , we note that the accounts for current generations do not follow a consistent pattern relative to those in the previous two methods, based on aggregate native and immigrant populations. The changes we do observe reflect the differences between the native profiles in Figure $3 a$ and $b$ and the aggregate profiles used in the earlier tables. However, given the predominance of natives in the population, the difference in profiles is not large. A second source of difference in the two methods of computing generational accounts is the fact that the populations used previously include varying shares of natives and immigrants at different ages. In particular, as Figure 4 shows, the immigrant share of the elderly in the base year is higher than that for the general population; a similar pattern exists for later years. Because the elderly are net transfer recipients, the previous methodology tends to overstate the transfers expected by those in middie age, for it attributes to a primarily native group the future transfers received by both natives and immigrants. This explains why the accounts in this third set of columns are higher in middle age.

Thus, considering immigrants and natives separately does affect our estimates of generational accounts. However, because this methodology also separates immigrants from future generations of natives, the net effect of the correction on our estimate of generational imbalance is minor. This can be seen by comparing the entries for the "\% difference" for males and females and the "\% change" in taxes and transfers with those corresponding to the previous case, which did not separate immigrants and natives.

Before considering the effect of immigration itself, we implement one further change in methodology. As the discussion of the profiles in Figures $1-3$ just noted, the characteristics of recent immigrants may be an inaccurate guide to the characteristics of future immigrants. In particular, given the important change in the mix of immigrants since the 1965 repeal of national-origin quotas that favored immigration from. Europe, the second-generation children of the past few decades' firstgeneration immigrants may have very different characteristics from the second-generation immigrants of today. If these future second-generation immigrants have lower skills and hence lower tax profiles than simple extrapolation suggests, we may understate the size of the existing fiscal imbalance (for future natives will have to shoulder more of the burden) and, more importantly for our purposes, overstate the fiscal benefits of immigration. To avoid this, we adjust the profiles of future 


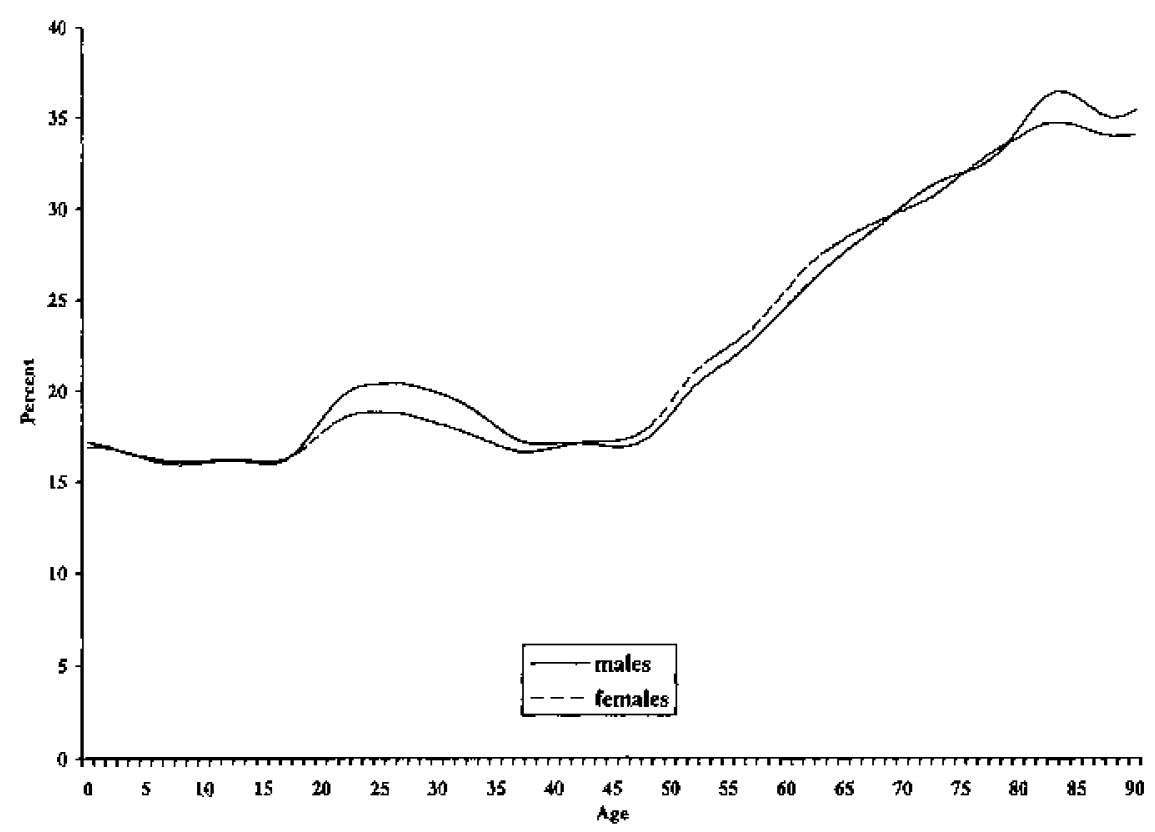

FIGURE 4. Share of Immigrants (First and Second Generation) in Total Population, 1998

second-generation immigrants in the following manner, which we describe briefly here and in more detail in the appendix.

We utilize an alternative set of population projections provided by Barry Edmonston, corresponding to the case in which all new immigrants to the United States ceases after the year 2000. This set of projections takes account not oly of the direct effect of a drop in first-generation immigrants, but also drop in the second-generation immigrant and native descendents of these excluded immigrants. Hence, by comparing the two sets of population projections, we may calculate the number of secondgeneration immigrants present each year as a consequence of post-2000 immigration, i.e., the children of first-generation immigrants arriving after the year 2000 . Based on the educational characteristics of recent firstgeneration immigrants and estimated educational transition matrices, we then project the educational characteristics of these post-2000 secondgeneration immigrants, and adjust their tax and transfer profiles accordingly, using estimated profiles that distinguish by educational status.

The last set of generational accounts in Table 1 illustrates the effect of 
this adjustment. The accounts of current native generations are the same, as only future generations are affected by the adjustment. As expected, the projected net tax profiles of post-2000 second-generation immigrants fall. These adjusted profiles, shown in Figure $3 a$ and $b$, now lie slightly below the profiles for natives. This decline in projected net tax contributions raises the estimated fiscal imbalance. The effect is not large, in part because this difference in second-generation profiles has only a gradual influence over time. Still, we view this adjustment as appropriate, and treat this set of assumptions as the base case for our subsequent policy simulations.

In addition to the scenario just considered, in which all taxes and transfers are adjusted, the last two columns also present the accounts for the first future generation under the two alternative scenarios in which only taxes or only transfers are adjusted. When taxes and transfers are adjusted, a 7.3-percent increase in taxes and cut in transfers is required to restore fiscal balance. A 10.1-percent increase in taxes or a 25.8percent cut in transfers would be required if either set of instruments were adjusted separately. While all three policies have similar effects on current generations, note that the policy of adjusting only taxes falls more heavily on males, while that of adjusting only transfers falls more heavily on females.

These results suggest that the traditional method of computing generational accounts, which treats the entire population as native-born, has not been significantly biased in its conclusions regarding overall fiscal balance. However, with the new technique, we are now in a position to evaluate the impact of changes in immigration policy.

\section{THE IMPACT OF IMMIGRATION}

What impact would a change in immigration have on the fiscal burdens of current and future generations? To address this question, we must first specify the exact change in policy envisioned. While we do not consider it a realistic policy option, simply halting all immigration after the year 2000 provides a useful polar case for analyzing the impact of less extreme changes in policy as well. Thus, we consider such a policy, based on the alternative set of projections discussed in the previous section.

It is also necessary to specify a fiscal policy environment in which the change in immigration policy takes place. We consider two such environments. In the first, the burden of the government's intertemporal fiscal imbalance falls entirely on future generations. This corresponds to the simulations reported in Table 1 . In the second fiscal environment, gov- 
ernment's fiscal policy is assumed to change immediately, with taxes being raised and transfers being cut on all generations from the base year onward, until the government's fiscal imbalance is eliminated under the current immigration scenario. This policy leaves the current newborn and first future native generations with roughly the same generational accounts, adjusted for growth, with the very slight difference for males being attributable to differences in life expectancy. Note, too, that this policy implies a smaller burden on future generations than does the other scenario.

The effects of these alternative fiscal scenarios may be seen by comparing the first two and last two columns in Table 2, which present the burdens on current and future generations of males and females under the alternative fiscal policies. The first row under "future generations" corresponds to the case of present immigration policy. Reading across the table, we observe that stabilizing fiscal policy would require an increase of $\$ 2,300$ in the burden on newborn males, and $\$ 1,800$ in the burden on newborn females, corresponding to an immediate 1.3-percent increase in ail taxes and a 1.3-percent cut in all transfers. This immediate adjustment would permit a significant drop in the burdens on members of future generations, who, by assumption, would also face a 1.3percent increase in all taxes and a 1.3-percent cut in all transfers. "I

Now consider the impact of eliminating immigration. ${ }^{12}$ Eliminating immigrants also eliminates the taxes they pay and the transfers they receive. It may also have some impact on the level of government purchases, depending on what we wish to assume about the nature of these goods (i.e., "public" goods vs. "private" goods) and how their provision changes with population. Initially, we assume that government purchase profiles remain constant, meaning, for example, that a reduction in the population size with no change in population structure will induce a reduction of equal proportion in the level of government purchases.

Under this assumption about government purchases, the impact of eliminating immigration is shown in the second set of numbers labeled "Future generations" in Table 2. For the fiscal scenario that allocates the entire burden to future generations, eliminating immigration helps the remaining population, lowering the burden on males by $\$ 4,800$ and the burden on females by $\$ 3,700$. Thus, immigration acts against the

\footnotetext{
11 For this and all other simulations in the second set of columns in Table 2, the "\% change ${ }^{\prime \prime}$ refers to the change for future generations relatiwe to the baseline with no change in fiscal policy or immigration.

12 This policy simulation also eliminates the return migration of immigrants already in the United States.
} 
TABLE 2

Generational Accounts: The Effects of Immigration(a)

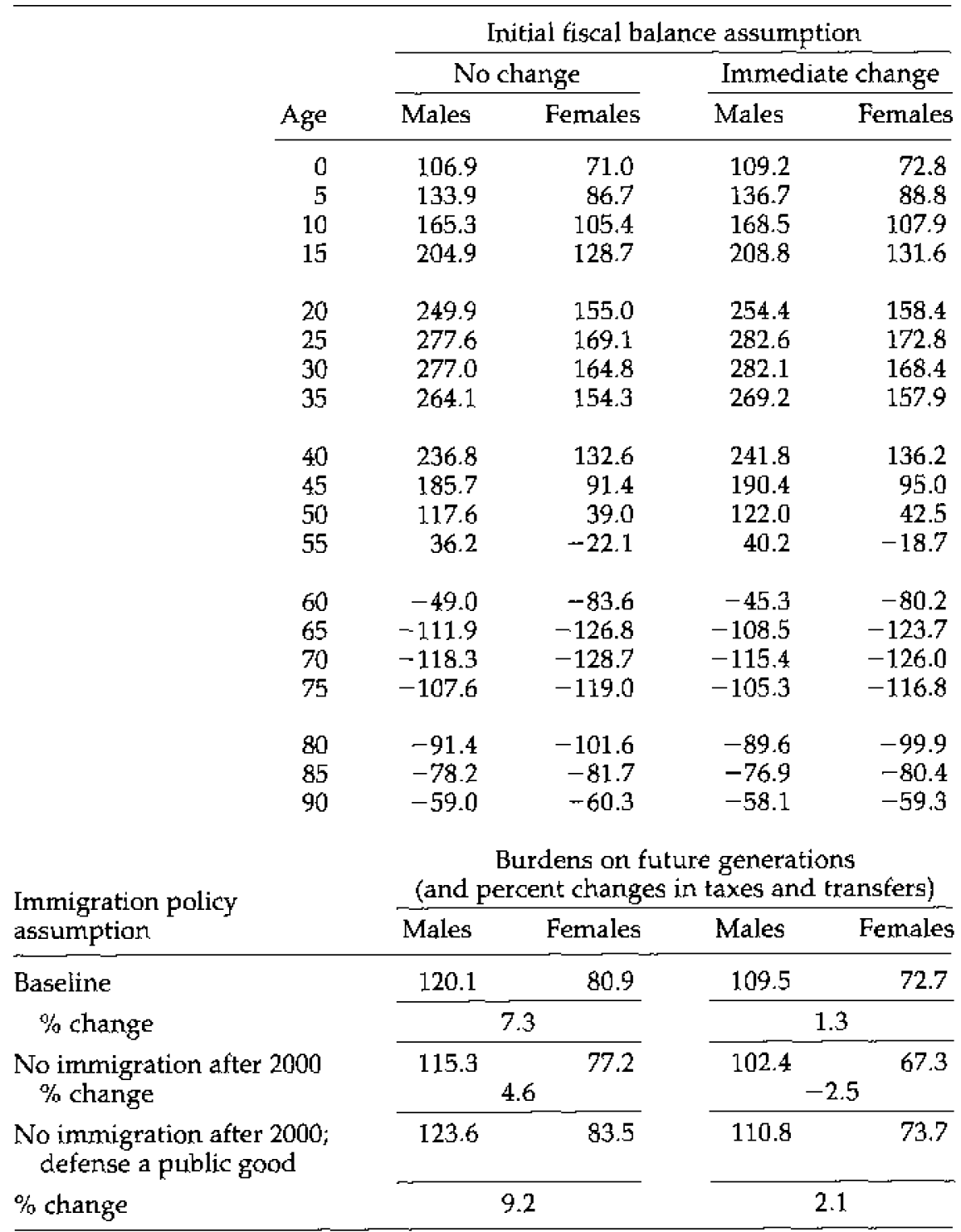

(a) In thousands of dollars; $r=.06, g=.012$. Base year 1998. 
restoration of fiscal balance. This picture is reinforced by the alternative assumption that fiscal policy is immediately adjusted to institute balance under present immigration policy. As shown in the table's last two columns, eliminating immigration now reduces the burdens on future males by $\$ 7,100$ and future females by $\$ 5,400$.

What explains the difference for the two fiscal policies? It is helpful to consider this in the context of equation (3), the government's intertemporal budget constraints. Under the "responsible" fiscal policy scenario, more of the burden is being placed on current generations, who make up the first term on the left side of equation (3), and less on future generations, who make up the second term on the left side. Immigrants in future generations are primarily new immigrants (whose presence in the United States would be eliminated by the reform), ${ }^{13}$ while those in current generations include some new immigrants but also all immigrants already present in the United States. Hence, new immigrants account for a greater fraction of this second term than of the first: their fiscal contribution, relative to that of others in the population, is weighted more strongly toward future generations. Thus, their average contribution is lower under the policy of immediate adjustment, which raises burdens on those included in both terms, than under the policy of "letting future generations pay," which raises burdens only on those accounted for by the second term. Therefore, eliminating new immigrants from the population has a more favorable impact under the scenario of immediate fiscal adjustment. ${ }^{14}$

This conclusion hinges, of course, on our assumption regarding the change in government purchases, 1.5 and in some sense represents an extreme case in which there are no economies of scale in the consumption of the goods and services government provides. While this may be a reasonable assumption for some government-provided goods and services, there may be others for which a public-goods nature implies significant economies of scale in consumption. Perhaps the most likely

13 We say "primarily" because, under the policy considered, there will still be some secondgeneration immigrants born in the future to first-generation immigrant parents who arrived before the elimination of immigration.

14. Indeed, in our earlier paper (Auerbach and Oreopoulos, 1999), we found an even larger difference between the results corresponding to the "irresponsible" and "responsible" scenarios, to the extent that extra immigration provided a nef fiscal benefit in the former case. The reason is that, under our previous fiscal projections, the fiscal gap and hence the net burden on future generations was substantially larger than is currently projected.

t5 Recall that only government purchases, not all government spending, is relevant here, because transfer payments are already incorporated in the generational accounts, and interest payments ar'e excluded to avoid double counting. 
candidate for this latter category is spending on national defense. In 1998 , U.S. defense spending was $\$ 340$ billion, or 23 percent of consumption and investment spending by all levels of government combined, down slightly as a percentage compared to years past. Thus, we consider as an alternative case the assumption that a quarter of all government purchases are purely "public" in nature, and do not vary at all with the size of the immigrant population. This may also be somewhat extreme, as one would expect the size of the military and the defense budget to respond to at least some extent to large changes in population. On the other hand, there may be other components of federaI, state, and local purchases with a "public" component.

Treating a portion of government purchases as unrelated to population size means that eliminating immigrants has no impact on this amount, which will make reducing immigration appear less attractive from the fiscal perspective. The last set of numbers labeled "future generations" in Table 2 illustrates the effect of this change in assumption. Now, under both scenarios, eliminating immigration after the year 2000 harms the native population. The largest losses are under the "irresponsibility" scenario, for which future immigrants would bear a larger share of the fiscal burden. In this case, future native males lose $\$ 3,500$, and future females lose $\$ 2,600$. Even these losses, which may also be viewed as the implied gains from having immigrants present, are smaller than the potential gains these generations would achieve through immediate fiscal balance already considered in the table. Thus, given that the immigration policy being considered involves a much larger change in immigration than is feasible, it appears that simple changes in the level of immigration would have small fiscal impacts, when compared to the overall U.S. fiscal imbalance.

To examine the sensitivity of these conclusions, we consider variations of two types. In each instance, to keep the number of cases manageable, we do not consider the cases in which fiscal adjustment affects all generations (corresponding to the second set of columns in Table 2). Table 3 repeats the calculations of Table 2 for different assumptions about the future fiscal policies to be used to produce fiscal balance. The top panel of the table, reproduced from Table 2 , assumes equal percentage changes in taxes (which are increased) and transfers (which are reduced). The second panel assumes that only tax increases are used, while the third panel assumes that only cuts in transfers are used. While the numbers differ across the three simulations, these differences are small and the patterns are the same.

Table 4 presents the results for alternative interest-rate and growthrate assumptions, reporting the percentage change in taxes and transfers 
TABLE 3

Burdens on Future Generations:

Altemative Fiscal Policy Tool(a)

\begin{tabular}{|c|c|c|}
\hline \multirow{2}{*}{$\begin{array}{l}\text { Immigration policy } \\
\text { assumption }\end{array}$} & \multicolumn{2}{|c|}{ Change $(\%)$} \\
\hline & Males & Females \\
\hline & \multicolumn{2}{|c|}{ Taxes and transfers } \\
\hline Baseline & 120.1 & 80.9 \\
\hline$\%$ change & \multicolumn{2}{|c|}{7.3} \\
\hline No immigration after 2000 & 115.3 & 77.2 \\
\hline$\%$ change & \multicolumn{2}{|c|}{4.6} \\
\hline $\begin{array}{l}\text { No immigration after } 2000 ; \\
\text { defense a public good }\end{array}$ & 123.6 & 83.5 \\
\hline \multirow[t]{2}{*}{$\%$ change } & \multicolumn{2}{|c|}{9.2} \\
\hline & \multicolumn{2}{|c|}{ Taxes only } \\
\hline Baseline & 121.9 & 80.7 \\
\hline$\%$ change & \multicolumn{2}{|c|}{10.1} \\
\hline No immigration after 2000 & 115.7 & 77.0 \\
\hline$\%$ change & \multicolumn{2}{|c|}{6.3} \\
\hline $\begin{array}{l}\text { No Immigration after } 2000 ; \\
\text { defense a public good }\end{array}$ & 124.3 & 83.1 \\
\hline \multirow[t]{2}{*}{$\%$ change } & \multicolumn{2}{|c|}{12.6} \\
\hline & \multicolumn{2}{|c|}{ Transfers only } \\
\hline Baseline & 118.1 & 81.2 \\
\hline$\%$ change & \multicolumn{2}{|c|}{25.8} \\
\hline No Immigration after 2000 & 114.4 & 77.7 \\
\hline$\%$ change & \multicolumn{2}{|c|}{17.0} \\
\hline $\begin{array}{l}\text { No Immigration after } 2000 \\
\text { defense a public good }\end{array}$ & 121.6 & 84.5 \\
\hline$\%$ change & \multicolumn{2}{|c|}{34.0} \\
\hline
\end{tabular}

(a) In thousands of dollars; $r=.06, g=012$. Base year 1998 . 
TABLE 4

Percentage Change in Taxes and Transfers: Sensitioity Analysis

\begin{tabular}{|c|c|c|c|c|}
\hline \multirow[b]{2}{*}{$\begin{array}{l}\text { Int. } \\
\text { rate }\end{array}$} & \multirow[b]{2}{*}{$\begin{array}{l}\text { Growth } \\
\text { rate }\end{array}$} & \multicolumn{3}{|c|}{ Change $(\%)$} \\
\hline & & Baseline & $\begin{array}{l}\text { No immigration } \\
\text { after } 2000\end{array}$ & $\begin{array}{l}\text { No immigration after } 2000 \\
\text { defense a public good }\end{array}$ \\
\hline \multirow[t]{3}{*}{.03} & .007 & 20.8 & 21.1 & 24.8 \\
\hline & .012 & 14.7 & 14.9 & 18.9 \\
\hline & .017 & 9.0 & 9.1 & 13.3 \\
\hline \multirow[t]{3}{*}{.06} & .007 & 11.7 & 8.9 & 13.5 \\
\hline & .012 & 7.3 & 4.6 & 9.2 \\
\hline & .017 & 2.0 & -0.8 & 3.8 \\
\hline \multirow[t]{3}{*}{.09} & .007 & -14.7 & -22.7 & -16.9 \\
\hline & .012 & -16.8 & -24.6 & -18.8 \\
\hline & .017 & -21.3 & -29.2 & -23.4 \\
\hline
\end{tabular}

for the three immigration scenarios. As the table shows, the percentage increase (decrease) in taxes (transfers) needed to satisfy the government's budget constraint falls both with increasing discount rate and with increasing rate of productivity growth. That latter result reflects the fact that tax revenues will grow more quickly. The former result is due to the pattern of projected taxes and spending, with cash-flow surpluses in the short run followed by cash-flow deficits. High rates of return would allow these short-run surpluses to translate into very large accumulations that would be more than sufficient to cover long-run needs, making the current imbalance negative for a 9-percent rate of return, one that is perhaps too high to provoke serious contemplation.

Moving from top to bottom in the table, we see that immigration is generally most helpfut, and reducing immigration most harmful, when the baseline fiscal imbalance is large. For a discount rate of 3 percent, reducing immigration raises burdens under both assumptions regarding the response of defense spending. For a 6-percent discount rate, the central case, reducing immigration is helpful if defense spending falls, but harmful if it does not. For a 9-percent discount rate, reducing immigration is always helpful, because it leaves fewer individuals to divide the fiscal dividend.

To summarize our finding thus far, reducing immigration might increase or reduce future fiscal burdens, with the outcome depending primarily on how large overall future burdens will be. However, the rate of immigration is only one possible immigration policy change. One might expect that adjusting the mix of immigrants toward the more highly 
Fiscal Effects of U.S. Immigration 149

skilled could have a significant fiscal impact, based on the large differences in fiscal profiles by educational status reported in NRC (1997). This is also the conclusion reached by Storesletten (2000) in a recent simulation analysis. Hence, we turn now to consider the impact of this type of policy shift.

\section{A CHANGE IN THE COMPOSITION OF THE NEW IMMIGRANT POPULATION}

Immigration policy based on the "typical" immigrant ignores the considerable heterogeneity of the immigration population. Though recent immigrants, on average, are less educated than their U.S. counterparts, they include among their number higher percentages of both college graduates and those without high school diplomas. For example, among recent male immigrants to the United States, 36.2 percent have not completed high school, and 30.5 percent are college graduates. For native males, the corresponding percentages are 14.4 percent and 26.3 percent, respectively (NRC, 1997, p. 183). Thus, given that the composition of the immigrant population is not immutable, an evaluation of the fiscal effects of immigration is seriously incomplete if it does not also consider the effects of changes in the education levels of immigrants.

As in the case of changes in rate of immigration already discussed, we start with an extreme case here, for the sake of clarity, not realism. We suppose that, beginring after the year 2000, the United States alters its immigration policy so that all subsequent immigrants have at least some education beyond high school. We assume that all first-generation immigrants arriving after 2000 have the tax and transfer profiles estimated for such immigrants. We also consider the additional effect that this change in skill mix has on the educational status of future second-generation immigrants born to these post-2000 first-generation immigrants.

The results of this exercise are presented in Table 5, under the assumption that there is no immediate fiscal policy change and that, ultimately, taxes and transfers of future generations are all adjusted proportionally. The table presents four sets of results. The first panel corresponds to the base case from earlier tables. The second presents the new policy, incorporating the effects on first-generation immigrants. The third panel presents the full policy impact, taking into account also the effect on future second-generation immigrants. The fourth panel presents the full results for a less extreme intermediate policy that applies the new rule to half the new immigrant population, leaving the remaining half of immi- 
TABLE 5

Burdens on Newborns and Future Generations: Alternative Immigration Policies ${ }^{(4)}$

\begin{tabular}{|c|c|c|}
\hline & Males & Females \\
\hline \multicolumn{3}{|l|}{ Base case } \\
\hline $\begin{array}{l}\text { Newborns } \\
\text { Future generations }\end{array}$ & $\begin{array}{l}106.9 \\
120.1\end{array}$ & $\begin{array}{l}71.0 \\
80.9\end{array}$ \\
\hline$\%$ change & & \\
\hline
\end{tabular}

Alt new 1st-generation immigrants with education $>$ HS

\begin{tabular}{lll} 
Newborns & 106.9 & 71.0 \\
Future generations & 101.9 & 66.9 \\
\cline { 2 - 3 }$\%$ change & \multicolumn{3}{|c}{-2.9} \\
\hline
\end{tabular}

Incorporating induced 2 nd-generation immigrant effects

\begin{tabular}{llll} 
Newborns & 106.9 & 71.0 \\
Future generations & 101.1 & 66.3 \\
\cline { 2 - 3 }$\%$ change & \multicolumn{3}{|c}{-3.4} \\
\cline { 2 - 3 }
\end{tabular}

Policy applied to only $50 \%$ of the new immigrant population

\begin{tabular}{llll} 
Newborns & 106.9 & & 71.0 \\
Future generations & 110.5 & & 73.5 \\
\cline { 2 - 4 }$\%$ change & \multicolumn{3}{c}{1.9} \\
\hline
\end{tabular}

(a) In thousands of dollars; $r=.06, g=.012$. Base year 1998 .

grants as projected under the base case. This intermediate policy would, for example, increase the share of new 25-year-old immigrants with more than a high-school education from 39 to 70 percent, while reducing the share with less than a high-school education from 37 to 18 percent.

As the table shows, the full policy would have a significant fiscal impact on native cohorts, reducing the burden on future generations by $\$ 19,000$ for males and $\$ 14,600$ for females, an effect substantially larger than would be produced by immediate fiscal reforms to eliminate the imbalance between current and future generations, and much larger still than the impact of eliminating immigration entirely. Even the partial policy would reduce future burdens by $\$ 9,600$ and $\$ 7,400$, respectively, nearly the impact of eliminating the current fiscal imbalance. 


\section{CONCLUSIONS}

Our findings suggest a number of conclusions. First, even an enormous change in the rate of immigration-simulated as an outright immigration ban after the year 2000-has a small impact on fiscal balance relative to the size of the overall imbalance itself. Thus, more realistic changes in the level of immigration should be viewed neither as a major source of the existing imbalance nor as a potential solution to it.

Second, the net fiscal cost or benefit from immigration depends on the extent to which the existing fiscal imbalance will be borne by future generations. Because new immigrants and their offspring represent a larger fraction of future generations than of present ones, shifting the burden onto future generations also shifts it, relatively, onto new immigrants. When a policy of "fiscal responsibility" is followed, with taxes and/or transfers adjusted immediately on all generations to restore the government's intertemporal budget constraint, the fiscal gain from immigration is reduced, or the loss increased.

Third, the overall fiscal impact of immigration is unclear. Whether there is a gain or a loss depends on the extent to which government purchases rise with the immigrant population. We considered two extreme cases. When defense spending rises in proportion to population size, immigration worsens the fiscal imbalance. When defense spending is a "pure" public good, unaffected by population size, immigration lessens the fiscal imbalance.

Finally, a change in immigration policy that alters the composition, rather than the level, of immigration does have the potential to reduce the fiscal burdens on future generations. A policy that would earmark half of the current level of immigration flow for individuals with at least some postsecondary education would have roughly the same impact on future generations as a policy that eliminated the fiscal gap. Thus, as concerns fiscal policy, altering the mix of immigrants appears to be a more important policy decision than the altering the Ievel.

In producing these results, we have also extended the methodology of generational accounting to accommodate heterogeneity among members of current and future generations other than the distinction by sex that has been present in prior work. To deal with the very different tax and transfer profiles of immigrants and natives, we developed an alternative method of calculating fiscal imbalance that does not require the assumption of equal percentage changes in lifetime tax burdens. An obvious application of this methodology would be to the construction of generational accounts that recognize other forms of heterogeneity within generations, notably by lifetime income class. 


\section{APPENDIX}

This appendix describes the method used to construct profiles broken down by age, sex, and nativity, and the further adjustment of the profiles of post-2000 second-generation immigrants to allow for their differences from current second-generation immigrants.

\section{A.1 Combining Profiles from Two Sources}

Our first step is to combine two sets of tax-transfer profiles, one broken down only by age and sex and the other broken down by age and nativity, to generate estimated profiles broken down by age, sex, and nativity. Our procedure is the same for each age, and so age is omitted from the discussion. The algorithm uses data from three sources. The first set of data is population projections, provided by Barry Edmonston. These projections are broken down by nativity $i$ (equal to 1,2 , or 3 for first-generation immigrants, second-generation immigrants, and all others) and sex $j$ (taking a value of $m$ for males or $f$ for females), $P_{i^{i}}^{i}$ The second set of data is the tax and transfer profiles by sex, used by Gokhale et aI. (GPS, 1999). These profiles, $\bar{r}_{i}(j=m, f)$ are expressed as ratios, normalized by the values for 40 -year-old males. The third set of data is the tax and transfer profiles by nativity, constructed by Lee and Miller (1997), which we denote $T^{i}(i=1$, $2,3)$. We seek to use these data to construct normalized profiles for taxes and transfer by sex and nativity, $r_{i}^{i}$.

Before applying our algorithm to combine these two sets of profiles, it is necessary for us to make their categories compatible. GPS apply profiles that have been used and described in earlier generational accounting work for the United States, for example Auerbach, Gokhale, and Kotlikoff (1991). Each male and female at each age is assigned a profile, relative to that of a 40-year-old male, for six categories of taxes (labor income, FICA, excise, capital income, property, and seignorage) and seven categories of transfer payments (OASDI, Medicare, Medicaid, UI, general welfare, AFDC, and food stamps). For purposes of estimating government expenditures (which are not included in the generational accounts), the methodology uses separate federal and state and local government purchase profiles. Our calculations are based on these same tax, transfer, and government consumption groupings, although we wish to distinguish by immigrant status as well.

To construct profiles for immigrants, we use average per capita amounts from Lee and Miller (1997) for first- and second-generation immigrants and natives, for males and females combined. ${ }^{16}$ However, these

16 See also National Research Council (1997) for a detailed discussion of these profiles 
profile categories are broader than the ones used by GPS. For taxes, these are: state and federal income, FICA, property, sales, and federal business and excise taxes. For transfers, 25 different local, state, and federal programs are used: OASDI, Medicare, Medicaid (noninstitutional), Medicaid (institutional), SSI, AFDC, school lunch, food stamps, Special Supplemental Nutrition Program for Women, Infants, and Children (WIC), energy assistance, rent subsidy, public housing, earned income tax credit, unemployment insurance, elementary and high school, bilingual education, public college, federal student aid, incarceration costs, federal retirement, military retirement, railroad retirement, workers' compensation. state and local retirement, and refugee assistance.

Lee and Miller (1997) aggregate individuals into five-year age groups, beginning with $0-4$ and ending with $80+$. To convert their data into individual age amounts, we assume that individual cohorts in each fiveyear age grouping have identical values. In some cases where the relative immigrant profiles of Lee and Miller were zero for cohorts below age 15 while profiles for males and females were non-zero, those cohorts under 15 were assumed to have the same relative immigrant profile values as the $15-19$ group.

The categories are then aggregated to fit those used by GPS by adding the per capita amounts. For example, federal and state income taxes are combined into one category, while institutional and noninstitutional Medicaid expenditures are combined into another. Many of the smaller categories from Lee and Miller (1997) were reclassified as part of either state or federal government consumption.

To construct the normalized tax and transfer profiles by sex and nativity, $r_{j}^{i}$, we start by requiring that they be consistent with the two sets of profiles we already have; that is,

$$
\begin{aligned}
& \underbrace{r_{m}^{i} P_{m}^{i}+r_{f}^{j} P_{f}^{i}}_{r_{m}^{3} P_{m}^{3}+r_{f}^{3} P_{f}^{3}}=\frac{T^{i}\left(P_{m}^{i}+P_{f}^{i}\right)}{T^{3}\left(P_{m}^{3}+P_{f}^{3}\right)}, \quad i=1,2, \\
& r_{j}^{1} P_{j}^{1}+r_{j}^{2} P_{j}^{2}+r_{j}^{3} P_{j}^{3}=\bar{r}_{j}\left(P_{j}^{1}+P_{j}^{2}+P_{j}^{3}\right), \quad j=m, f .
\end{aligned}
$$

This gives us four equations in the six unknowns $r_{j^{*}}^{i}$ To obtain the two additional equations needed for a solution, we assume that the relative profile for males and females are the same across the three groups, i.e., 


$$
\frac{r_{m}^{i}}{r_{j}^{i}}=\frac{r_{m}^{3}}{r_{f}^{3}}, \quad i=1,2
$$

Using these six equations for each age group, we solve for the relative profiles by sex, immigrant status, and age, which are used in turn to compute the generational accounts.

\section{A.2 Distinguishing Immigrants by Education Level}

Our base-case analysis adjusts the profiles of post-2000 second-generation immigrants to take account of the fact that they are likely to differ from current second-generation immigrants with respect to education level. This adjustment requires three further steps: first, the construction of profiles that vary by education level; second, the derivation of population weights corresponding to each education category, to construct new aggregate profiles; and finally, the identification of the share of future second-generation immigrants associated with post-2000 immigration, i.e., the children of post-2000 first-generation immigrants.

While we adjust profiles only for post-2000 second-generation immigrants in our baseline analysis, our alternative simulation of a policy of accepting more highly educated immigrants after the year 2000 also requires adjustment of future first-generation profiles. Thus, we need profiles for both groups that distinguish by level of education, as well as by age and sex.

These profiles are created in a similar way to that described above. Using the same notation, we now add a third dimension of educational status to the profiles we already have, and to the population shares. We distinguish the profiles for first- and second-generation immigrants by those with less than high school education, those with high school education, and those with more than high school education:

$\frac{r_{m}^{i, e} P_{m}^{i, e}+r_{f}^{i, e} P_{f}^{i, e}}{r_{m}^{i} P_{m}^{i}+r_{f}^{i} P_{f}^{i}}=\frac{T^{i_{,} e}\left(P_{m}^{i_{i} e}+P_{f}^{i, e}\right)}{T^{i}\left(P_{m}^{i}+P_{f}^{i}\right)}, \quad i=1,2, \quad e=<\mathrm{HS}, \mathrm{HS},>\mathrm{HS}$.

We want to solve for the profiles $r_{m}^{i_{e} e}$ and $r_{f}^{i, e}$. From the previous section, we already have the imputed values $r_{s}^{i}$. From Lee and Miller (1997), we have the tax and transfer profiles already used above that are broken down by nativity, $T$, as well as profiles also broken down by level of education, $T^{i, e}$. Two additional assumptions are required to obtain a unique solution for the profiles we seek. First, we assume that the relative profiles in each immigrant group are the same for each education subgroup: 


$$
\frac{r_{m+e}^{i, e}}{r_{f}^{i, e}}=\frac{r_{m}^{i}}{r_{f}^{i}}, \quad i=1,2, \quad e=<\mathrm{HS}, \mathrm{HS},>\mathrm{HS} .
$$

Second, we assume the male-female split within each education group is the same for the specific immigrant group as a whole:

$$
\frac{P_{m}^{i, e}}{P_{f}^{i, e}}=\frac{P_{m}^{i}}{P_{f}^{i}}, \quad i=1,2, \quad e=<\mathrm{HS}, \mathrm{HS},>\mathrm{HS} .
$$

From (A4), (A5), and (A6) we can then solve for the relative profiles of immigrant generations by educational status:

$$
r_{s}^{i, e}=\frac{T^{i, e}}{T^{i}} r_{s}^{i}, \quad i=1,2, \quad e=<\mathrm{HS}, \mathrm{HS},>\mathrm{HS}, \quad s=m, f
$$

To use the profiles in equation (A7) to construct aggregate profiles for post-2000 second-generation immigrants, we need population weights for the different education categories. We assume that such immigrants are the children of first-generation immigrants with the educationalstatus breakdown of current first-generation immigrants between the ages of 25 and 45, as estimated by Lee and Miller (1997). We then use the intergenerational educational transition matrices of Lee and Miller to calculate the share of post-2000 second-generation immigrants in each education category, and use these weights to construct profiles for post2000 second-generation immigrants.

To estimate the share of post- 2000 second-generation immigrants, we difference the two sets of population projections provided by Barry Edmonston, corresponding to current immigration policy and a cutoff of immigration in the year 2000 . If we ignore changes in emigration between the two scenarios, then the differences in first- and second-generation immigrants identify the number of first-generation immigrants in the population after 2000 who arrive after 2000 , and their second-generation offspring. In our base-case calculations, we assign separate profiles to the post-2000 second-generation population.

For the alternative simulation in which we assume a change in the educational mix of first generation immigrants, we construct new aggregate profiles for post-2000 first-generation immigrants, based on the new assumed population shares for each education category, and then revise the aggregate profiles for post-2000 second-generation immigrants as well, applying the educational transition matrices to the new assumed first-generation population shares. 


\section{REFERENCES}

Auerbach, Alan J., Jagadeesh Gokhale, and Laurence J. Kotlikoff (1991). "Generational Accounts: A Meaningful Alternative to Deficit Accounting." In Tax Policy and the Economy, vol. 5, D. Bradford (Ed.). Cambridge, MA: MIT Press.

Awerbach, Alan J, and Laurence J. Kotlikoff (1999). "The Methodology of Generational Accounting." In Generational Accounting around the World A. Auerbach, L. Kotlikoff, and W. Leibfritz (Eds.). Chicago: University of Chicago Press.

Auerbach, Alan J., and Philip Oreopoulos (1999). "Analyzing the Fiscal Impact of U.S. Immigration." American Economic Review Papers and Proceedings, May: $176-180$.

Bonin, Holger, Bernd Raffelhüschen, and Jan Walliser (1998). "Can Immigration Alleviate the Demographic Burden?" Universität Freiburg, June.

Borjas, George ]. (1994). "The Economics of Immigration." Joumal of Economic Literature, December: 1607-1717.

Card, David (1996). "Immigration Inflows, Native Outflows, and the Local Labor Market." Princeton Industrial Relations Section Working Paper no. 368. November.

Fehr, Hans, and Laurence J. Kotlikoff (1999). "Generational Accounting in General Equilibrium." In Generational Accounting around the World, A. Auerbach, L. Kotlikoff, and W. Leibfritz (Eds.). Chicago: University of Chicago Press.

Gokhale, Jagadeesh, Benjamin R. Page, and John R. Sturrock (1999). "Generational Accounting for the United States: An Update." In Generational Accounting around the World, A. Auerbach, L. Kotlikoff, and W. Leibfritz (Eds.). Chicago: University of Chicago Press.

Lee, Ronald D., and Timothy Miller (1997). "Immigrants and Their Descendants." Project on the Economic Demography of Interage Income Reallocation, Department of Demography, University of California, Berkeley.

National Research Council (1997). The New Americans. Washington: National Academy Press.

Storesletten, Kjetil (2000). "Sustaining Fiscal Policy through Immigration." Forthcoming in Journal of Political Economy. 